\section{Тренды страховой медицины}

П.н. ТЕСля, кандидат экономических наук, Новосибирский государственный технический университет. E-mail: teslia_pavel@list.ru

В статье кратко анализируется современное состояние российской страховой медицины на фоне мировых тенденций. Показано, что страховая схема - далеко не единственный и не обязательно самый эффективный способ организации финансирования здравоохранения. Указаны некоторые «болевые точки» страховой медицины.

Ключевые слова: страховая медицина, институциональная структура здравоохранения, потери эффективности

Страховая медицина - явление очень недавнее: она возникла в Западной Европе только в XIX - начале XX века. Примерно в это же время, особенно в эпоху реформ Александра II, в сфере медицины принципы социальной помощи, основанные на методах страхования, стали внедряться и в России [1].

Существует множество разнообразных финансовых схем здравоохранения. Так, за услуги медицины платить можно «из кармана» (именно так называется эта форма оплаты в статистике Всемирной организации здравоохранения), можно из бюджета государства, как это было во времена Советского Союза и как до сих пор живут британцы, или из фондов страхования, обязательного или добровольного, как это происходит сейчас во многих странах мира.

Россия переживает драматический период реформ в сфере здравоохранения, одной из целей которых декларировалось повышение эффективности, резко упавшей в начале 1990-х годов. Однако не только в России, но и во всем мире идут процессы потери эффективности медицины и роста экономического бремени, происходящего из сферы здравоохранения.

Доля расходов в мире на медицину стабильно росла после 1970-х годов с 6\% до сегодняшних 12\% ВВП. Среди причин повышение благосостояния, способствующее росту расходов на медицину, увеличение доли населения, обеспечиваемого социальным страхованием, старение, а также эффект Баумоля, который гласит: в сфере услуг производительность отстает от реального сектора, а зарплата растет вместе с другими секторами. Это увеличивает издержки на услуги и неизбежно требует повышения тарифов и цен на лекарства. Отсюда - рост доли расходов на здравоохранение в составе ВВП. Но наиболее тревожащим трендом стало увеличение доли растрачиваемых впустую ресурсов здравоохранения из-за монополизма, ошибок, неоптимальности предоставленных услуг, коррупции и мошенничества, которые, по оценкам ВО3, составляют от 20 до 40\% [2].

Несовершенство рыночных механизмов здравоохранения вынуждает прибегать к государственному вмешательству - установлению стандартов, финансированию из бюджета и контролю со стороны надзорных органов. Масштабы государственного финансирования поистине колоссальны. И это повсеместно внушает тревогу, поскольку ведет к наращиванию госдолга и выходит из-под контроля. Это - одна из причин переноса центра тяжести на страховые финансы.

В России взят курс на реформирование здравоохранения с ориентацией на полное переключение со смешанной модели его финансирования на полностью страховую. Пока эта цель далека от осуществления и скорее всего не будет достигнута при ныне живущих поколениях.

\section{Финансовые потоки}

\section{на рынках медицинских услуг России}

Приведем статистику расходов на здравоохранение в Российской Федерации по источникам финансирования. ОМС - обязательное медицинское страхование - финансируется из ФОМС, специальных государственных внебюджетных фондов, территориальных и федерального. Помимо внебюджетных ФОМС граждане получают медицинские услуги также и за счет государственного бюджета. Частные источники - это средства «из кармана» и из фондов ДМС, образованных из добровольных страховых взносов (табл. 1).

Среднегодовые темпы прироста расходов на здравоохранение в России опережают темпы роста ВВП (табл. 2). Отметим, что ДМС, и так незначительное по масштабам, развивалось с наименьшими темпами, зато ОМС устойчиво лидировало. По годам доли разных источников финансирования были неравномерными (см. табл. 1). 
Таблица 1. Структура источников финансирования здравоохранения России в 1995-2013 гг. (здесь и далее - усреднение по подпериодам), долл. США по паритету покупательной способности

\begin{tabular}{|l|c|c|c|c|}
\hline \multicolumn{1}{|c|}{ Источник } & $\mathbf{1 9 9 5 - 2 0 0 0}$ & $\mathbf{2 0 0 1 - 2 0 0 5}$ & $\mathbf{2 0 0 6 - 2 0 1 0}$ & $\mathbf{2 0 1 1 - 1 0 1 3}$ \\
\hline ОМС & 15,9 & 30,0 & 109,5 & 159,7 \\
\hline $\begin{array}{l}\text { Государственное финансирование } \\
\text { кроме ОМС) }\end{array}$ & 29,2 & 44,2 & 144,7 & 221,3 \\
\hline Частное финансирование (кроме ДМС) & 78,2 & 99,3 & 316,0 & 513,5 \\
\hline ДМС & 5,3 & 9,3 & 19,9 & 21,2 \\
\hline Всего & 128,6 & 182,8 & 590,1 & 915,6 \\
\hline
\end{tabular}

Источник: данные ВОЗ и ВБ (выбраны для обеспечения однородности данных при проведении международных сопоставлений) [3, 4], расчеты автора.

\section{Таблица 2. Среднегодовые темпы прироста финансирования} здравоохранения России за 1995-2013 гг., \%

\begin{tabular}{|l|c|c|}
\hline \multirow{2}{*}{\multicolumn{1}{|c|}{ Источник }} & \multicolumn{2}{c|}{ В ценах } \\
\cline { 2 - 3 } & текущих & сопоставимых \\
\hline ОМС & 12,8 & 9,4 \\
\hline Государственное финансирование (кроме ОМС) & 11,6 & 8,2 \\
\hline Частное финансирование (кроме ДМС) & 11,0 & 7,6 \\
\hline ДМС & 8,4 & 5,1 \\
\hline Всего & 11,3 & 7,9 \\
\hline
\end{tabular}

Источник: данные ВОЗ, ВБ, ФРС [3, 4, 5], расчеты автора.

\section{Специфика рынка услуг здравоохранения}

Рынок медицинских услуг обладает рядом свойств, которые сильно отличают его от традиционных

1. Потребитель нуждается в здоровье, однако купить его он не в состоянии, поэтому он приобретает услуги медицины и смежных сфер деятельности (врачей, специалистов в области здорового образа жизни и питания, тренеров по лечебно-профилактической физкультуре и т. п.). В большинстве случаев результат полученной услуги непредсказуем. Поэтому определить с достаточно высокой точностью предстоящие затраты и результаты лечения зачастую невозможно.

2. Решение о наилучшем лечении принимает не пациент, который не обладает достаточной компетенцией, а врач. Поскольку оценить требующиеся затраты и результаты необходимо на объективных основаниях, для определения результативности (эффективности) медицинских услуг нужна третья сторона, т. е. независимый эксперт.

3. Доступ на рынок медицинских услуг жестко регламентируется - для этого требуется диплом, а также лицензии, аттестаты и т. п. различных ассоциаций, которые зачастую действуют как монополии, устанавливая нижние границы цен и тарифов, стандарты на качество услуг. Не случайно против усилий президента США Б. Обамы, направленных на реформу американского здравоохранения, медики США встали сплоченной стеной, не желая ослабления своей монопольной власти.

4. Спрос на услуги здравоохранения у каждого человека возникает в значительной степени непредсказуемо. Но поскольку рынок объединяет множество людей, то колебания совокупного спроса предсказать значительно проще. Со временем меняется характер и обычных заболеваний, что требует адаптации методов лечения и профилактики.

На «рынке здоровья» открывается широкий простор для разного рода аномалий. Иногда медики уклоняются от предоставления качественных услуг в должном объеме, требуют ненужных анализов и даже вредных процедур, а пациенты либо стремятся к избыточному потреблению уже оплаченных врачебных услуг, либо, наоборот, уклоняются от должной защиты собственного здоровья, нарушают предписания врачей. Отношения между участниками рынка сильно подвержены эффектам «принципал - агент» («начальник - подчиненный»). Информационная асимметрия приводит к тому, что страхователи опасаются получить больший риск, чем может быть покрыт запланированными затратами из страхового фонда, и тем самым не сокращают, а увеличивают специфический риск аномально высоких затрат на лечение отдельных граждан.

Все эти свойства рассматриваемой отрасли говорят в пользу применения разного рода смешанных государственно-страховых схем со всеми их сильными и слабыми сторонами.

\section{Платная или бесплатная медицина?}

Реформа здравоохранения, которое ранее финансировалось из бюджета, при переходе на смешанную модель сразу привела к появлению услуг, не подпадающих ни под ту, ни под другую систему. Некоторые заболевания оказались исключенными 
из пакета бесплатных услуг, но не вошли в состав базового страхового пакета. Если бюджета (в пределах нормативов) субъекта Федерации для компенсации средств ФОМС не хватает, то сразу же возникает дилемма: платить пациенту (или его родным) либо оставаться без врачебной помощи. Нарастание бюджетного дефицита приводит к тому, что отказывают в финансировании больным, чьи интересы не защищены мощными лобби и группами давления, это прежде всего неработающая часть населения и иммигранты.

Интерес чиновников состоит в обеспечении сбалансированности государственного бюджета и бюджетов субъектов Федерации. В этих целях, собственно, и предполагалось перевести все финансирование медицины на одноканальную систему - через фонды обязательного медицинского страхования. В принципе такая задача разрешима. В Монако, например, 99\% расходов на здравоохранение финансируется из фонда ОМС, на втором месте стоит Франция (95\%), в России же эта доля составляет только 41\%. Как совершить «большой скачок» от 41 до 100\%, никто не знает. Есть предположения, что для обеспечения сбалансированности бюджета ФОМС на всех уровнях потребуется увеличить взносы в ФОМС примерно в 1,5 раза, чтобы они составили около 6\% средней зарплаты [6].

Услуги, финансируемые через систему обязательного медицинского страхования, в настоящее время для пациента являются бесплатными. Однако зреет идея перевода части этих услуг на платную основу во избежание дефицита консолидированного бюджета страховой системы [7]. Численность тех, кто может подпасть под платный режим страхования, весьма значительна - около 35 млн человек. По замыслу Минфина, это коснется некоторых категорий неработающего населения. Пока до практической реализации идея платности еще не доведена.

К вопросу о платности тесно примыкает вопрос - заботится ли сам застрахованный о своем здоровье? Если он наносит своему здоровью ущерб, это, разумеется, его добровольный выбор, но почему общество должно оплачивать последствия? Поэтому медицинские страховщики размышляют о том, чтобы контролировать поведение застрахованных лиц. Один из инструментов такого контроля - обязательная диспансеризация и требование исполнения пациентами предписаний врачей.
В случае нарушения - полная или частичная плата за обязательное медстрахование.

Идея обязательной диспансеризации, скорее всего, не пройдет. Она противоречит конституционным правам граждан, поскольку подрывает принцип бесплатной и общедоступной медицинской помощи.

Более приемлемый вариант - это введение частичной оплаты (софинансирования) медицинских услуг наряду с использованием бесплатного полиса медстрахования [8].

Поиск способов экономии средств социальных бюджетов идет непрестанно. В конце 2015 г. чиновники Минфина искали способ сокращения выплат на здравоохранение на 350 млрд руб. за счет ограничения визитов к терапевтам в поликлиниках, отмены бесплатных вызовов врачей на дом и многого другого, вплоть до идеи отказаться от содержания автотранспорта «скорой помощи» и использовать в режиме аутсорсинга услуги независимых транспортных компаний.

В целях экономии затрат обсуждается заимствование наилучшей зарубежной практики. Например - за счет сокращения числа коек до уровня ОЭСР, то есть почти вдвое (с 9,42 до 4,96 койки на 1000 населения) можно сэкономить 253 млрд руб. [9]. Больных предлагается помещать в дневной стационар, это якобы позволит увеличить оборачиваемость койки во много раз. В пример приводят опыт Норвегии, где около половины всех операций проводится в дневном стационаре. Еще один пример экономии дает Франция, где пациенты платят за вызовы «скорой помощи», признанные необоснованными.

Основной упор в части развития медицинских услуг предлагается сделать по линии добровольного, платного страхования. Чтобы подсластить пилюлю, Минздрав намерен предложить налоговый вычет для всех, кто им воспользуется. Сомнительно, однако, что это даст достаточно сильный стимул в контексте действующей системы подоходного налогообложения с ее плоской шкалой.

До сих пор добровольное страхование распространялось преимущественно в крупных городах и охватывало там около 5\% жителей (в целом по России за 2011-2013 гг. эта доля составляла вдвое меньшую величину - см. табл. 1). Основной формой ДМС было страхование работодателями. Не решенным 
в современной России является и вопрос: как должна производиться компенсация расходов для тех граждан, которые получают услуги по линии ДМС и в то же время продолжают делать взносы в фонды ОМС?

При существующей в России страховой схеме финансирования здравоохранения вместо бюджетной однозвенной модели построена трехзвенная, состоящая из федерального и территориальных фондов и огромного множества страховых компаний; через них протекает, постепенно мелея, пока не достигнет отдельного больного, поток страховых денег. Мы платим не только врачам, но и чиновникам фондов, и клеркам страховых компаний, а также их боссам.

Доля страховых денег, которая оседает в территориальных фондах ОМС, по официальным данным, сравнительно невелика Например, в 2015 г. ТФОМС по Новосибирской области из общей суммы расходов 26536 млн руб. только 128 млн руб. использовал по статье «Общегосударственные вопросы». Доля, которая достается страховым медицинским организациям (число их, включая региональные подразделения, свыше 210), по тем же официальным данным, более значительна - около $3 \%$ от суммы расходов на обязательное страхование. В 2014 г. это составляло около 15 млрд руб. Альтернативные источники говорят о более тяжелом бремени административных расходов. По данным ВОЗ, в России от 25 до 40\% собранных страховых взносов уходят на покрытие затрат ФОМС и страховых компаний [10].

В дополнение к сказанному есть и существенные косвенные трансакционные издержки.

При организации страхования необходимо определять состав услуг, видов лечения и профилактических мероприятий, подпадающих под базовые и территориальные программы медицинского страхования. Все, что в этот перечень не включено, должно быть оплачено за счет пациентов. У большинства людей денег на это нет. Средств ОМС и бюджетов хватает в России только на 42\% фактических расходов, остальное - платная медицина.

Тарифы и цены на бесплатные услуги и лекарства устанавливаются так, что даже элементарные, копеечные процедуры поликлиник и больниц возмещаются не в полной мере. Страховые тарифы не покрывают необходимые затраты даже по застрахованным услугам. Что лежит в основе такого положения- отдельный вопрос. Возможно, такая практика происходит из полулицемерного или полуискреннего стремления к бюджетной экономии.

Критериев эффективности работы страховых медицинских организаций не существует. В основном они организуют медицинскую экспертизу и прокачивают бюджетные деньги, но не отстаивают права пациентов, в том числе при необоснованных отказах в оказании бесплатной медицинской помощи. Страховщики порой могут и вредить больным, требуя от лечебного учреждения соблюдения стандартов и нормативов услуг даже в тех случаях, когда требуется индивидуальный режим лечения, например, в связи с осложнениями или из-за возрастных особенностей пациента Не случайно всерьез обсуждаются отказ от клятвы Гиппократа и отмена 41-й статьи Конституции России, гарантирующей право на бесплатную медицинскую помощь.

Медики постоянно твердят, что страховым компаниям нечего делать в системе здравоохранения, что они злоупотребляют высокими и необоснованными штрафами ${ }^{1}$. Причиной штрафа может быть, например, такое основание: «В записи врача диагноз записан неразборчиво».

\section{Страховая система: за и против}

Положительные отзывы о страховой системе здравоохранения исходят в основном от заинтересованных лиц, от тех, кто получает выгоду от ОМС - страховых компаний, чиновников, отчитывающихся о внедрении «прогрессивной финансовой модели», политических деятелей и т. п. Для нас важнее критика, исходящая от объективных наблюдателей. Вот что говорит доктор Л. Рошаль, всеми уважаемый эксперт, искренне заинтересованный в эффективности российской медицины: «Введение страховой системы у нас не привело ни к чему хорошему. Она не контролирует процесс лечения. Я думаю, что это был эксперимент, который нужно прекратить» [11]. В ответ на это заявление представители страховых компаний предлагают дополнить обязательное страхование добровольным. Контрдовод Л. Рошаля

${ }^{1}$ С этой позицией не согласны некоторые эксперты. Например, в Ниу «Высшаяшколаэкономики" считают, чтостраховыемедицинские организации сегодня уже не просто посредники - ихактивность в проведении экспертиз качества медпомощи существенно возросла [8]. 
таков: фактически это будут платные дополнительные медицинские услуги, за которые и сейчас 70\% населения не смогут заплатить.

С 2013 г., когда оплата услуг в рамках системы ОМС в медучреждениях стала производиться после перехода от частичного к полному тарифу в порядке реализации программы развития системы ОМС, внезапно выяснилось, что в ряде соседствующих друг с другом регионах России разрыв в стоимости одних и тех же услуг может составлять сотни процентов (при одинаковых районных коэффициентах). Причина в том, что на нормативы Министерства здравоохранения накладываются нормативы Минфина. Финансирование в регионах зависит от бюджетной обеспеченности, а тарифы «подтягиваются» под бюджет.

Высказываются соображения и о том, как усовершенствовать действующую систему. Например, предлагается, чтобы пациенты оплачивали часть расходов. Идея такого соплатежа в том, чтобы у больного был стимул полностью выполнять предписания врача. В этом случае часть уплаченных денег можно вернуть. Совместное финансирование должно стимулировать здоровых людей к профилактике возможных заболеваний, более здоровому образу жизни, питания. Во многих странах такая система действует давно. Но и это предложение - не более чем паллиатив для страны, где половина жителей находятся за чертой бедности.

\section{Способы финансирования здравоохранения в разных странах}

Выбор формы финансирования не зависит от степени развитости рыночных отношений в той или иной стране. В Великобритании, Италии, Дании, Бельгии, Норвегии, Канаде и ряде других стран действует преимущественно государственная система финансирования, в Германии и Франции - страховая. Преимущественно частная - в США. В России - смешанная бюджетно-страховая.

Рассмотрим зависимость объемов финансирования здравоохранения от душевого ВВП. Построим точечную диаграмму для парных координат, душевого ВВП и совокупных расходов на медицину из расчета на душу населения. Чтобы устранить эффект долларовой инфляции, все дальнейшие расчеты будем проводить в реальных ценах, используя для дефлирования индекс потребительских цен в США.
Расчеты по 190 странам за 2011-2013 гг. обнаруживают следующую картину: чем выше в данной стране объем ВВП на душу населения, тем больше там тратят на здравоохранение. Примечательно, пожалуй, что среди богатых стран в пяти из них на медицину тратят заметно больше остальных, а в нескольких расходы оказались неожиданно меньше средних. Возможным объяснением такой аномалии является достижение в этих странах плато по ожидаемой продолжительности жизни $[12,13]$, что могло послужить основанием для отказа от наращивания объемов финансирования. Однако данных статистики недостаточно, чтобы сделать более строгие выводы об имеющей место зависимости. Построим линию регрессии по данным 190 наблюдений для 190 стран за 2011-2013 гг. Результаты расчетов говорят о высокой статистической значимости связи между совокупными доходами и расходами на медицину: из каждого дополнительного доллара мирового ВВП 7,56 центов было потрачено на увеличение финансирования здравоохранения. Вместе с тем справедливо и обратное утверждение: сокращение ВВП отрицательно сказывалось на медицинских расходах, а вместе с ними - и на здоровье.

Сформулированный вывод справедлив и для нашей страны. Динамическая регрессионная зависимость между годовыми расходами на здравоохранение и ВВП за 1995-2013 гг., построенная на статистке ВОЗ и ВБ по России, показывает результат, близкий к рассмотренному выше, т. е. увеличение российского ВВП на 1 рубль способствовало увеличению совокупных расходов на здравоохранение на 6,67 коп.

Изучение связи между частными расходами на медицину и душевым ВВП (за 2011-2013 гг.) показывает: там, где меньше тратят частных денег на медицину, в действие вступает государство, которое «выправляет линию». В среднем по мировой экономике из каждого дополнительного доллара ВВП только 1,72 цента пойдет «из личного кармана» потребителя на цели здравоохранения - это в шесть с лишним раз меньше, чем из государственных средств.

Можно ли утверждать, что более богатые страны тратят большую долю своего ВВП на здравоохранение, чем бедные? Результаты расчетов по тем же 190 странам показали, что явной взаимосвязи не наблюдается: сложившаяся картина весьма хаотична. 
Как этот факт согласуется с обнаруженной выше сильной статистической зависимостью между уровнем душевого ВВП и душевыми расходами на здравоохранение? Попытаемся далее ответить на этот вопрос.

Насколько масштабно применяют в разных странах различные системы страхования медицинских расходов?

Сначала рассмотрим ОМС. В 2013 г. обязательное медицинское страхование отсутствовало в странах с общей численностью населения 1,27 млрд чел. (из 7,13 млрд чел. мирового населения). В эту группу входят 68 стран из 190 - и те, в которых душевой ВВП высок (Австралия, Бруней, Дания, Великобритания, Кувейт, Объединенные Арабские Эмираты, Саудовская Аравия, Швеция), и те, где не очень, но со здравоохранением дела обстоят не самым худшим образом (Беларусь, Бразилия, Казахстан, Куба, Латвия), однако большинство составляют страны с низким уровнем душевого ВВП и слаборазвитой системой здравоохранения, например, Бутан, Ботсвана, Чад, Эритрея.

В целом страны, не применяющие обязательное медицинское страхование, по средневзвешенному душевому ВВП (8960 долл.) не очень значительно отличаются от тех, где оно используется (11286 долл.). Но если исключить из этой группы стран наиболее богатые, то средневзвешенный душевой доход снизится до 5579 долл., а это уже заметная разница.

Приведем рассчитанный автором рейтинг стран по величине расходов из ОМС (табл. 3).

Таблица 3. Выборка из рейтинга расходов из фондов ОМС в 1995-2013 гг., долл. США (по паритету покупательной способности)

\begin{tabular}{|c|l|c|c|c|c|}
\hline Рейтинг & Страна & $\mathbf{1 9 9 5 - 2 0 0 0}$ & $\mathbf{2 0 0 1 - 2 0 0 5}$ & $\mathbf{2 0 0 6 - 2 0 0 1 0}$ & $\mathbf{2 0 1 1 - 2 0 1 3}$ \\
\hline 39 & Россия & 45 & 56 & 162 & 202 \\
\hline 1 & Люксембург & 3363 & 4303 & 5999 & 5848 \\
\hline 2 & Монако & 3850 & 4404 & 5996 & 5461 \\
\hline 3 & Нидерланды & 2059 & 2482 & 4636 & 4868 \\
\hline 4 & Швейцария & 2419 & 2664 & 3591 & 4573 \\
\hline 5 & Франция & 2893 & 2965 & 3805 & 3750 \\
\hline 6 & США & 2277 & 2843 & 3449 & 3734 \\
\hline 7 & Германия & 2958 & 2760 & 3468 & 3587 \\
\hline 8 & Бельгия & 1941 & 2252 & 3159 & 3381 \\
\hline 9 & Япония & 2551 & 2409 & 2651 & 3330 \\
\hline
\end{tabular}

Источник табл. 3-4: данные ВОЗ и ВБ, расчеты автора.
Россия со своим 39-м местом вплотную идет за такими странами, как Черногория, Болгария, Македония и Панама. Примечательно, что наша страна быстро сокращала разрыв. Быстрее России наращивание финансирования из фондов ОМС происходило только в Китае (в начале 2010-х гг. - 44-е место; в середине 1990-х годов из фондов ОМС на здравоохранение направлялось 12 долл. на человека, в начале 2010-х годов - уже более 130 долл.). Во второй в мире по численности населения стране, Индии, ОМС было ничтожным по масштабам: на человека там приходилось чуть больше доллара страхового финансирования в год.

Считается, что в США страховая медицина развита относительно слабо, однако благодаря системам «Medicare» (помощь при госпитализации) и «Medicaid» (помощь бедным) страна оказалась на шестом месте по объемам финансирования из фондов ОМС.

Добровольное медицинское страхование по территориальному охвату превзошло ОМС: в странах, где оно не применялось, жили только 646 млн чел. Но в эту группу, за исключением Норвегии, вошли только бедные страны, где средний душевой доход был почти в три раза меньше, чем в странах с преимущественно добровольным страхованием. Таким образом, ДМС применяют более широко, но не столь интенсивно (в плане его доли в расходах на медицину), как ОМС. И хотя ДМС существенно уступает ОМС по масштабам и удельному весу в структуре финансовых источников медицины, его абсолютный объем, выраженный в долларах по ППС, возрастал почти повсюду, включая Россию (табл. 4).

Таблица 4. Выборка из рейтинга расходов из фондов ДМС в 1995-2013 гг., долл. США (по паритету покупательной способности)

\begin{tabular}{|c|c|c|c|c|c|}
\hline $\begin{array}{c}\text { Рей- } \\
\text { тинг }\end{array}$ & Страна & $\mathbf{1 9 9 5 - 2 0 0 0}$ & $\mathbf{2 0 0 1 - 2 0 0 5}$ & $\mathbf{2 0 0 6 - 2 0 0 1 0}$ & $\mathbf{2 0 1 1 - 2 0 1 3}$ \\
\hline 64 & Россия & 4,1 & 9,1 & 19,3 & 19,2 \\
\hline 1 & США & 2037,5 & 2672,1 & 2964,2 & 3057,7 \\
\hline 2 & Швейцария & 719,8 & 607,6 & 712,7 & 762,0 \\
\hline 3 & Канада & 303,5 & 435,2 & 633,9 & 726,0 \\
\hline 4 & Франция & 477,7 & 505,8 & 661,3 & 674,5 \\
\hline 5 & Ирландия & 180,9 & 247,2 & 491,8 & 610,6 \\
\hline 6 & Нидерланды & 562,9 & 823,2 & 488,7 & 524,5 \\
\hline 7 & Австралия & 219,2 & 219,8 & 340,0 & 518,3 \\
\hline 8 & Германия & 338,2 & 357,6 & 475,6 & 493,7 \\
\hline 9 & Багамы & 444,2 & 443,6 & 456,8 & 415,5 \\
\hline
\end{tabular}

2 ЭКО - 2016. - №11 
Россия, занимающая 64-е место, находится между Парагваем и Швецией. Китай занимает 77-е место, его расходы в начале 2010-х годов - около 10 долл. на человека, а в Индии - около 1,5 долл.

\section{О результатах применения}

\section{национальных медицинских страховых систем}

Как следует из опросов, многие российские работодатели считают, что страховая медицина так и не заработала в России из-за недостаточного финансирования [14]. Однако финансирование вряд ли является основной причиной ее неудовлетворительного состояния. Сопоставимая с Россией по населению и экономике Мексика с расходами на здравоохранение в 6,2\% ВВП (в России - 6,5\%) в 2014 г. заняла 12-е место в мировом рейтинге эффективности здравоохранения агентства Bloomberg (а Россия - только 51-е).

Данный феномен присущ отнюдь не только России. Так, США, хотя и лидируют с большим отрывом по доле расходов на здравоохранение в ВВП, по принятому в ВОЗ показателю оценки функционирования занимают только 37-е место. В Дании и Португалии ожидаемая продолжительность жизни примерно одинакова, но Португалия тратит в расчете на одного своего гражданина на 1/3 меньше, чем Дания [15].

Одна из важнейших причин отставания России - попытка добиться эффективности при неуклюже организованной структуре страхового рынка. В России имеется избыточно много страховых организаций. А в самых успешных странах их число невелико и/или быстро сокращается. Например, во Франции их всего три. А там, где эффективность услуг здравоохранения страдает, количество таких организаций неоправданно велико. Вместо усиления конкуренции и создания благоприятных условий для застрахованных (в особенности при добровольном страховании) компании ужесточали отбор клиентов и создавали для людей затруднения доступа к дешевым, но качественным услугам. Самые страдающие слои населения России - неработающие и иммигранты. Наряду с этим в российских СМИ можно найти много примеров того, как людям навязывают дорогостоящие услуги, в то время когда можно сделать несложную и сравнительно недорогую операцию. Как это часто случается, рынок дает сбои, когда участники сделок наделены информацией и компетенцией несимметрично - врач обладает знаниями, которых у пациента нет. Особенно это ярко проявляется при предоставлении высокотехнологичних услуг. Нормативные документы и процедуры мотивируют медицинских работников настойчиво предлагать их пациентам, даже когда в этом нет необходимости, поскольку их вознаграждение привязано к финансовым потокам.

Известны также критические замечания руководителей медицинских учреждений о неэффективном распределении и использовании медицинской техники в частных компаниях: дорогостоящего оборудования много, но оно простаивает или используется намного менее интенсивно, чем это могло быть при нерыночной или хорошо организованной рыночной системе здравоохранения.

Все эти феномены были известны давно. Вот почему во избежание дискриминации неработающих в рамках страховой модели Бисмарка страхованию (и медицинскому, и социальному) подлежали только работающие люди, для остальных действовало бюджетное финансирование.

В Германии и Голландии в 1980-х гг. наблюдалось многое из того, чем страдает современное российское здравоохранение. В частности, там обострилась проблема неблагоприятного отбора: страховые медицинские компании стали отказывать в страховых услугах клиентам из групп риска. Это потребовало вмешательства государства. Были приняты законы, которые обязывали страховщиков обслуживать всех, кто к ним обращался. Для поддержания конкуренции был введен порядок соплатежей. Люди стали выбирать между страховыми медицинскими организациями, ориентируясь и на тарифы, и на качество контроля за лечебными учреждениями, обеспечиваемого этими организациями. В США после введения в 2014 г. системы общедоступного здравоохранения, названной в народе «Обамакэр», компании также были обязаны страховать всех граждан. При недостатке средств клиентов страховых компаний необходимое финансирование производится из федерального бюджета. Это, разумеется, не устраивало консерваторов из Конгресса, они обвиняли Обаму в непомерной нагрузке на федеральный бюджет и в попытке протащить в Америку социализм. 
Оплата амбулаторной помощи на принципах подушевого финансирования, принятая в России в качестве базовой схемы, вполне приемлема в странах с высокой долей городского населения - как в Европе, а в России такая модель может функционировать успешно лишь в нескольких крупных городах, но не в остальной части страны. Положение будет ухудшаться по мере реализации принятой стратегии развития специализированных услуг в ущерб укреплению общей терапевтической практики. Специализированная помощь в России, вместо того чтобы стать более доступной для тех, кто в ней нуждается, будет в одних районах перегружена и неэффективна, а в других останется невостребованной и также неэффективной.

Множественность и переменчивость источников финансирования и состава пакетов услуг, установленных в России на федеральном и на региональном уровнях, порождает проблему неопределенной ответственности. Пациентам часто бывает непонятно, надо ли платить за лечение, или оно где-то «прописано» как бесплатное. В таких условиях в медицинских учреждениях есть соблазн взимать плату, а также пользоваться «неформальными» схемами финансирования. Чтобы решить эту проблему, например, в Словакии в составе министерства здравоохранения было создано специальное информационное государственное агентство, куда можно обратиться с жалобами, если от пациента требуют незаконные платежи за оплачиваемые государством медицинские услуги [15].

\section{Выводы}

1. Обязательное медицинское страхование применяется в большинстве стран мира. Вместе с тем далеко не везде полностью отказались от бюджетного финансирования здравоохранения. Если кто-то захочет апеллировать к мировому опыту, отстаивая важность одноканального медицинского финансирования, эта аргументация будет несостоятельной. Как свидетельствует мировой опыт, внедрение страховой медицины происходит в основном там, где уровень благосостояния достаточно высок. При этом в некоторых богатых странах, как показывает опыт Германии, Голландии и США, страховые модели здравоохранения дополняются элементами нерыночного характера, а государственный бюджет не устраняется из числа источников финансирования.
2. Успех страховой медицины зависит от ее правильной институциональной организации. Если государство при создании системы страхования не проявит достаточной силы власти и не будет пользоваться хорошо продуманным планом, для чего необходим соответствующий административный ресурс, страховая медицина вместо того, чтобы создавать правильные стимулы и обеспечивать условия повышения эффективности, станет причиной возникновения дополнительных трансакцонных издержек и ложной мотивации. Проблемы развития российской страховой медицины в первую очередь возникли из-за недостаточности административного ресурса, непродуманной и ошибочной стратегии реформирования.

3. Попытки перевода российского здравоохранения на одноканальную, полностью страховую схему организации денежных потоков оказываются безуспешными. Этот провал не случаен. Мировой опыт говорит, что «чистых» страховых моделей в мире крайне мало. Социальные издержки такого перевода могут оказаться слишком велики. Ускоренный переход от нерыночного бюджетного финансирования к обязательному и добровольному страхованию как единому рыночному механизму финансирования создаст колоссальные межрегиональные диспропорции, и без того недопустимо большие. Кроме региональных, возникают также классовые и социальные диспропорции. Смешанная форма финансирования здравоохранения является вынужденной и, судя по мировому опыту, наиболее естественной для современных экономик.

4. Для того, чтобы как-то «починить» российскую страховую медицину, необходимо радикальным образом реорганизовать деятельность медицинских страховых организаций и переориентировать соответствующие надзорные органы на укрепление и реорганизацию деятельности медицинских учреждений. Цель этих органов должна состоять не только в выявлении и устранении нарушений, но и в конструктивной работе, подобно тому, как, например, организована деятельность Банка России с проблемными коммерческими банками.

\section{Литература}

1. Качаева Т. М., Дей А. А. Исторические аспекты становления страховой медицины // Тихоокеанский медицинский журнал. - 2015. № 1. - С. 96-100. 
2. The economics of public health care reform in advanced and emerging economies / eds. Clements B., Coady D., and Gupta S. - Washington, D.C.: International Monetary Fund, 2012.

3. Всемирная организация здравоохранения URL: http://apps.who. int/gho/data/view.main.HEALTHEXPRATIORUS?lang=en (дата обращения: 28.09.2016).

4. Всемирный банк. URL: http://data.worldbank.org/indicator/ NY.GDP.PCAP.PP.CD (дата обращения: 28.09.2016).

5. Федеральная резервная система США, публикация Федерального Банка Луизианы. URL: https://research.stlouisfed.org/fred2/series/ CUUR0000SAOR/downloaddata (дата обращения: 28.09.2016).

6. Модели системы обязательного медицинского страхования. URL: http://www.polarmed.ru/health.insurance/types/mandatory/models?from. page=\%2Fhealth.insurance\%2Ftypes\%2F (дата обращения: 30.09.2016). 7. URL: http://www.insur-info.ru/news/3932/ (дата обращения: 11.09.2016).

8. URL: http://www.insur-info.ru/press/112697/ (дата обращения: 11.09.2016).

9. Газета.Ru. - 2015. - 19 нояб.

10. Мамедова Л. Страховая медицина выгодна только чиновникам// Правда. - 2016. - 28 янв. URL: http://www.pravda.ru/society/family/ medicine/28-01-2016/1290283-medicina-0/ (дата обращения: 30.09.2016).

11. Рошаль: страховая медицина в России - эксперимент, который нужно прекратить. 27.01.2014. URL: http://doctorpiter.ru/articles/8369/ (дата обращения: 11.04.2016).

12. Улумбекова Г.Э. Здравоохранение России: мифы, реальность, решения. URL: http://rusrand.ru/analytics/analyticszdravoohranenie-rossiimify-realnost-reshenija (дата обращения: 28.04.2016).

13. Улумбекова Г. Э. Здравоохранение России. Что надо делать. - 2-е изд. - М.: ГЭОТАР-Медиа, 2015. - 704 с.

14. Российская бизнес-газета. - 2015. - 17 нояб.

15. Tompson W. Healthcare Reform in Russia: Problems and Prospects// OECD Working Papers, 2006. URL: www.oecd.org/eco/working.papers (дата обращения: 03.09.2006). 